\title{
The palisade cartilage tympanoplasty technique: a systematic review and meta-analysis
}

\author{
Caroline C. Jeffery ${ }^{1,2}$, Cameron Shillington ${ }^{2}$, Colin Andrews ${ }^{2}$ and Allan $\mathrm{Ho}^{1,2^{*}}$
}

\begin{abstract}
Background: Tympanoplasty is a common procedure performed by Otolaryngologists. Many types of autologous grafts have been used with variations of techniques with varying results. This is the first systematic review of the literature and meta-analysis with the aim to evaluate the effectiveness of one of the techniques which is gaining popularity, the palisade cartilage tympanoplasty. PubMed, EMBASE, and Cochrane databases were searched for "palisade", "cartilage", "tympanoplasty", "perforation" and their synonyms.
\end{abstract}

Main body of abstract: In total, 199 articles reporting results of palisade cartilage tympanoplasty were identified. Five articles satisfied the following inclusion criteria: adult patients, minimum 6 months follow-up, hearing and surgical outcomes reported. Studies with patients undergoing combined mastoidectomy, ossicular chain reconstruction, and/or other middle ear surgery were excluded. Perforation closure, rate of complications, and post-operative pure-tone average change were extracted for pooled analysis. Study failure and complication proportions that were used to generate odds ratios were pooled. Fixed effects and random effects weightings were generated. The resulting pooled odds ratios are reported. Palisade cartilage tympanoplasty has an overall take rate of $96 \%$ at beyond 6 months and has similar odds of complications compared to temporalis fascia (OR 0. $89,95 \% \mathrm{Cl} 0.62,1.30)$. The air-bone gap closure is statistically similar to reported results from temporalis fascia tympanoplasty.

Conclusions: Cartilage palisade tympanoplasty offers excellent graft take rates and good postoperative hearing outcomes for perforations of various sizes and for both primary and revision cases. This technique has predictable, long-term results with low complication rates, similar to temporalis fascia tympanoplasty.

Keywords: Tympanoplasty, Palisade, Cartilage, Type I, Perforation, Tympanic membrane

\section{Background}

Tympanoplasty or tympanic membrane (TM) repair is one of the most commonly performed surgeries in Otolaryngology-Head and Neck surgery, with various types of graft and techniques advocated in the literature. The use of cartilage for tympanic membrane repair is well described [1-3] and has reported benefits of long-term graft survival, low recurrence and infection rates, and decreased development of tympanic membrane retraction pockets over time [3-5]. Authors have reported

\footnotetext{
* Correspondence: entalberta@gmail.com

${ }^{1}$ Division of Otolaryngology-Head and Neck Surgery, University of Alberta, Hospital, 8440112 Street, Edmonton, AB T6G 2B7, Canada

${ }^{2}$ Faculty of Medicine and Dentistry, University of Alberta, Hospital, 8440112 Street, Edmonton, AB T6G 2B7, Canada
}

excellent functional results for small and large perforations [6-8] and often combine tympanoplasty with other middle ear procedures [2]. Cartilage tympanoplasty comprises a heterogeneous group of techniques including that the cartilage-perichondrium composite graft, diced cartilage, butterfly techniques, and palisade cartilage tympanoplasty [9-11].

Tos M. reviewed 23 different cartilage tympanoplasty methods and grouped them into six categories from A to $F$ [10]. The palisade technique is considered a form of Group A cartilage tympanoplasty. The palisade technique specifically involves placement of 0.5 to $3-\mathrm{mm}$ thick pieces of cartilage placed side by side and often overlapping, under the TM remnant until the defect is 
covered [9]. This technique has been used with recurrent perforations, adhesive otitis media or tympanic membrane retractions and other mixed middle ear pathologies $[12,13]$. Although several authors have reported success with this technique, we aimed to systematically review the literature on the use of cartilage palisades in Type 1 tympanoplasty and report clinical outcomes of this procedure including hearing and overall graft survival rate.

\section{Methods}

\section{Search}

A comprehensive search was undertaken using MEDLINE (from 1966), EMBASE (from 1980), CINAHL (from 1982), SCOPUS, and DissAbs in August, 2016. The keywords used were palisade, tympanoplasty, tympanic membrane, tympanic membrane perforation, ear drum, cartilage, and their synonyms. No limitation was placed on date or type of study.

\section{Inclusions/Exclusion}

Abstracts of articles obtained from search strategies were independently reviewed by three authors CS, CJ and CA for further assessment. Strict inclusion and exclusion criteria were set a priori. English articles and non-English articles with accurate English translation were included. Studies were excluded if they included only pediatric cases, were case reports or reviews or the study design precluded the ability to extract palisade tympanoplasty data. Articles describing the clinical outcomes of palisade cartilage tympanoplasty were then reviewed in full and subjected to further inclusion and exclusion analysis. Studies describing palisade cartilage tympanoplasty performed in conjunction with other middle ear or mastoid surgery (e.g. concurrent ossicular chain reconstruction, mastoidectomy, etc.) were excluded. Specifically, only studies reporting hearing outcomes beyond 6 months were included. In addition to strict inclusion and exclusion criteria, the quality of studies were further assessed by grading their level of evidence based on the Oxford Centre for Evidence-Based Medicine Levels of Evidence for Therapy Studies [13].

\section{Data extraction}

Data was then extracted from all articles, including patient demographics, study design, comparison groups, hearing outcomes, perforation closure rates and complications. Two authors extracted the data while a third verified the data extracted. Discrepancies were resolved by consensus. Specific outcomes of interest include graft success with at least 6 months follow-up, closure of the air-bone gap, and complications including middle ear infections, failure of graft survival, persistent perforation or otorrhea.

\section{Data synthesis and meta-analysis}

Microsoft Excel (2016) was used to maintain extracted data and articles. Clinical outcomes from studies were pooled to determine rates of failure and complications in the cartilage palisade treatment group versus control. The overall take-rate represents with proportion of studies with complete closure of tympanic membrane perforation at 6 months or beyond. Study-specific odds ratios were calculated to obtain the odds of complications for both treatment and comparator groups. Both random effects and fixed effects models were applied to yield confidence intervals for pooled estimates of odds ratios.

\section{Results}

The initial search yielded 199 articles, of which 163 were unique. Through screening of titles and abstracts, 114 were excluded based on initial criteria. The remaining 49 articles were reviewed then screened in detail by examining the full text and 44 more articles were excluded. Specifically, ten of the articles excluded were commentaries or reviews. Another nineteen articles were excluded due to their surgical method; some studies combined results for adult and pediatric patients or patients had concurrent middle ear (e.g. ossicular chain reconstruction) and mastoid surgery. Five more studies were excluded due to the lack of outcome measures or inadequate length of follow up. Ten more articles were excluded due to inability to obtain accurate English translations. This left 5 articles. Figure 1 is a flowchart of literature retrieved, application of inclusion and exclusion criteria, and resulting articles.

Of the included articles, 4 were retrospective studies and one was a prospective study. All articles compared their palisade group to a temporalis fascia group, and one also included patients undergoing repair with tragal perichondrium. Follow-up varied from 6 to 48 months. However, for analytical purposes, the results corresponding to the longest available follow-up time were used. See Table 1 for characteristics and level of evidence of included studies.

Khan et al. [14] included patients with both "small" and "large" perforations and is by far the largest study, with 390 total patients reported. Kazikdas et al. [12], Sishegar et al. [15] and Demirpehlivan et al. [16] only included subtotal perforations, with the defect being described as more than $50 \%$ of the area of the whole tympanic membrane. Vashishth et al. [17] selected patients for fascia or palisade group based on various risk factors. Specifically, the authors excluded patients with craniofacial abnormalities, revision tympanoplasties, near-total/ total perforations, and persistently discharging ears from the fascia group. However, he did include these difficult to treat patients in the palisade group. 


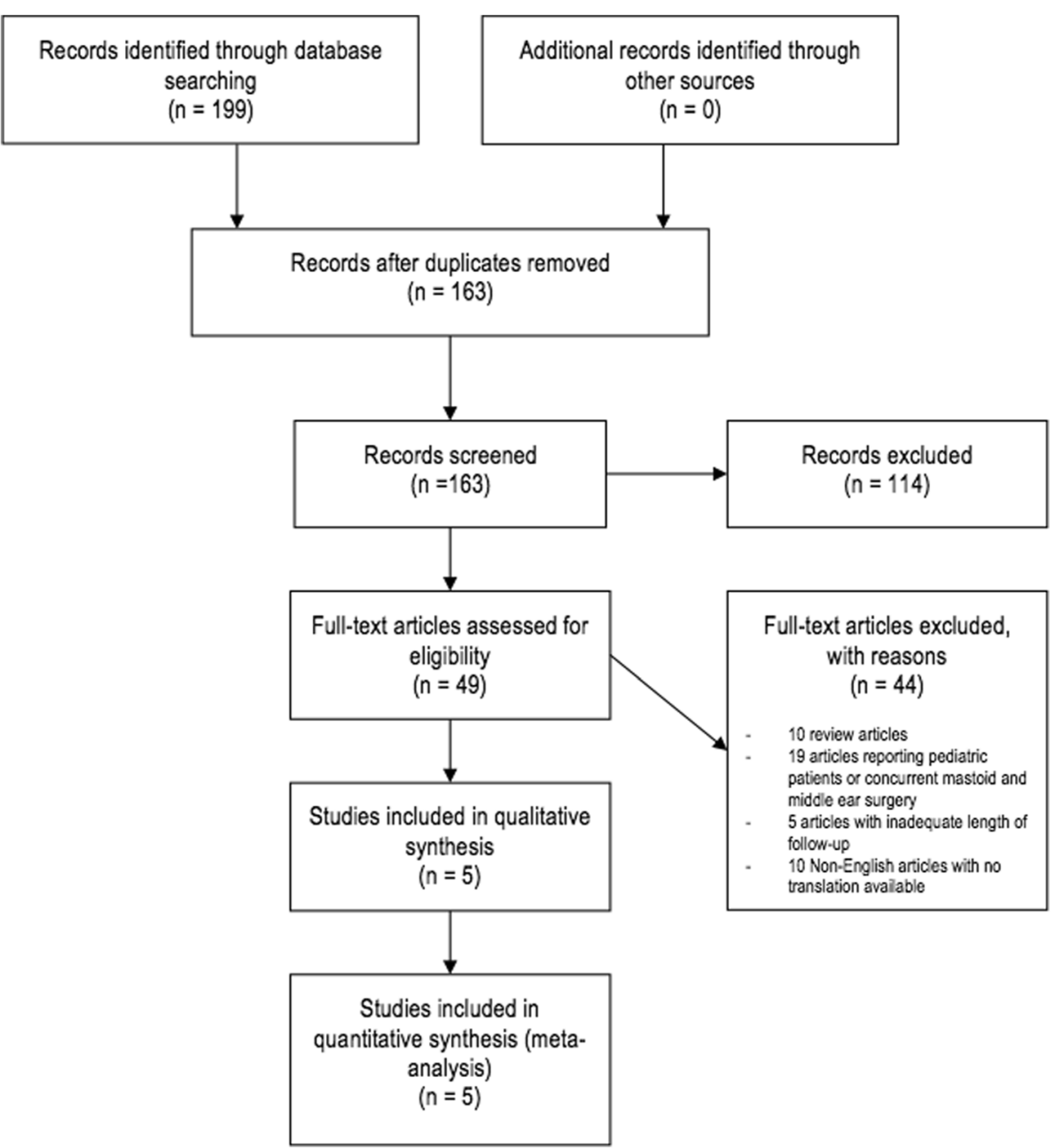

Fig. 1 PRISMA Flow Diagram

Table 1 Summary of included articles

\begin{tabular}{|c|c|c|c|c|c|c|c|}
\hline Authors & Type of Article & $\begin{array}{l}\text { Number of } \\
\text { Patients Total } \\
\text { (Palisade) }\end{array}$ & Comparators & $\begin{array}{l}\text { Mean Age } \\
\text { (Range) }\end{array}$ & $\begin{array}{l}\text { Follow-up in } \\
\text { months (Range) }\end{array}$ & $\begin{array}{l}\text { Level of Evidence } \\
\text { (Oxford Scale of } \\
\text { Evidence) }\end{array}$ & Size of Defect \\
\hline Khan et al. [14] & $\begin{array}{l}\text { Retrospective } \\
\text { cohort study }\end{array}$ & $390(223)$ & Temporalis fascia & $(11-57)$ & $\begin{array}{l}24 \text { and } \\
48 \text { months }\end{array}$ & III & Both small and large \\
\hline Kazikdas et al. [12] & $\begin{array}{l}\text { Retrospective } \\
\text { cohort study }\end{array}$ & $51(23)$ & Temporalis fascia & 27.6 & $\begin{array}{l}\text { Mean } 18.7 \\
\text { months (7-33) }\end{array}$ & III & $\begin{array}{l}\text { Subtotal perforations } \\
\text { (perforation }>50 \% \text { of } \\
\text { the whole TM) }\end{array}$ \\
\hline Shishegar et al. [15] & $\begin{array}{l}\text { Prospective } \\
\text { cohort study }\end{array}$ & $54(27)$ & Temporalis fascia & 30 & 6 months & $\|$ & Subtotal perforations \\
\hline Vashishth et al. [17] & $\begin{array}{l}\text { Retrospective } \\
\text { cohort study }\end{array}$ & $90(30)$ & Temporalis fascia & 24 & 12 months & III & $\begin{array}{l}\text { Total/near total perforations } \\
\text { excluded from fascia group, } \\
\text { included in palisade }\end{array}$ \\
\hline $\begin{array}{l}\text { Demirpehlivan } \\
\text { et al. [16] }\end{array}$ & $\begin{array}{l}\text { Retrospective } \\
\text { cohort study }\end{array}$ & 120(19) & $\begin{array}{l}\text {-Temporalis fascia } \\
\text {-Tragal } \\
\text { perichondrium }\end{array}$ & $(15-64)$ & $\begin{array}{l}\text { Minimum } \\
12 \text { months }\end{array}$ & III & Subtotal perforations \\
\hline
\end{tabular}


Table 2 Individual study results, graft take rates and complication rates for cartilage palisade tympanoplasty compared to temporalis fascia

\begin{tabular}{|c|c|c|c|c|c|c|c|c|}
\hline \multirow[t]{2}{*}{ Authors } & \multicolumn{3}{|l|}{ Palisade } & \multirow[b]{2}{*}{ Type of Complications } & \multicolumn{4}{|c|}{ Temporalis fascia } \\
\hline & $\begin{array}{l}\text { Number of } \\
\text { Patients }\end{array}$ & $\begin{array}{l}\text { Overall } \\
\text { take rate }\end{array}$ & Complications & & $\begin{array}{l}\text { Number of } \\
\text { Patients }\end{array}$ & $\begin{array}{l}\text { Overall } \\
\text { take rate }\end{array}$ & Complications & $\begin{array}{l}\text { Types of } \\
\text { Complications }\end{array}$ \\
\hline Khan et al. [14] & 223 & $97.8 \%$ & $10.0 \%$ & $\begin{array}{l}\text { Persistent or recurrent } \\
\text { perforation, otorrhea, } \\
\text { infection }\end{array}$ & 167 & $82.6 \%$ & $17.3 \%$ & $\begin{array}{l}\text { Persistent or recurrent } \\
\text { perforation }\end{array}$ \\
\hline Kazikdas et al. [12] & 23 & $95.7 \%$ & $8.7 \%$ & Perforation, otorrhea & 28 & $75.0 \%$ & $17.4 \%$ & $\begin{array}{l}\text { Persistent or recurrent } \\
\text { perforation }\end{array}$ \\
\hline Shishegar et al. [15] & 27 & $100.0 \%$ & $4.3 \%$ & Infection, otorrhea & 27 & $93.0 \%$ & $25.0 \%$ & $\begin{array}{l}\text { Persistent or recurrent } \\
\text { perforation }\end{array}$ \\
\hline Vashishth et al. [17] & 30 & $90.0 \%$ & $0.0 \%$ & & 60 & $83.3 \%$ & $18 \%$ & $\begin{array}{l}\text { Persistent or recurrent } \\
\text { perforation, otorrhea, } \\
\text { infection }\end{array}$ \\
\hline $\begin{array}{l}\text { Demirpehlivan et al. } \\
\text { [16] }\end{array}$ & 19 & $79.0 \%$ & $10.0 \%$ & $\begin{array}{l}\text { Persistent or recurrent } \\
\text { perforation, infection }\end{array}$ & 67 & $80.6 \%$ & $16.7 \%$ & $\begin{array}{l}\text { Persistent or recurrent } \\
\text { perforation }\end{array}$ \\
\hline Weighted average (SE & & $\begin{array}{l}96.0 \% \\
(1.1 \%)\end{array}$ & $3.1 \%(1.0 \%)$ & Weighted average (SE) & & $\begin{array}{l}82.5 \% \\
(2.0 \%)\end{array}$ & $17.9 \%(2.1 \%)$ & \\
\hline
\end{tabular}

SE Standard Error

Individual study results, pooled graft-take rates and complication rates for palisade tympanoplasty versus comparator are found in Table 2 . The pre-operative and post-operative air-bone gaps are reported in Table 3 along with average reduction in air-bone gap. The extracted proportion of patients experiencing complications in the palisade tympanoplasty and comparator groups were then used to generated odds ratios (OR). A weighted analysis of pooled ORs indicates no statistical difference in the odds of complications between palisade tympanoplasty and temporalis fascia tympanoplasty (i.e. confidence interval includes 1.0). Using a fixed effects model, which assumes fixed treatment effects, the overall odds ratio was 0.77 (95\% CI 0.50, 1.20). Using a random effects model, which accounts for variability of treatment effects between studies, the overall odds ratio was statistically similar at 0.89 (95\% CI 0.62, 1.30). Figure 2 demonstrates the forest plot for individual study OR estimates and the final overall estimate obtained by the two weighting methods.

\section{Discussion}

The results of this systematic review and meta-analysis are clinically significant. Overall, the palisade cartilage tyampanoplasty technique has excellent functional results for Type 1 tympanoplasty with a 96\% take rate at beyond 6 months. The air-bone gap closure is statistically similar to reported results from temporalis fascia tympanoplasty. Complications rates and long-term failure rates appear statistically and clinically comparable to tympanoplasty using temporalis fascia with no difference in the odds ratio of the two groups based on meta-analysis $(0.89,95 \% \mathrm{CI}$ : 0.62 to 1.30 ). While this systematic review specifically excluded studies that reported results of palisade cartilage tympanoplasty combined with other procedures, an overall graft take rate of $>97 \%$ has been reported in patients with who underwent combined palisade tympanoplasty with mastoidectomy for pathologies such as as cholesteatoma, adhesive otitis, and chronic mucosal disease $[13,18]$. Our results are consistent with previous

Table 3 Audiologic outcomes of included studies

\begin{tabular}{|c|c|c|c|c|c|c|}
\hline \multirow[t]{2}{*}{ Authors } & \multicolumn{3}{|l|}{ Palisade } & \multicolumn{3}{|l|}{ Temporalis fascia } \\
\hline & $\begin{array}{l}\text { Average Pre-operative } \\
\text { ABG }\end{array}$ & $\begin{array}{l}\text { Average Post-operative } \\
\text { ABG }\end{array}$ & $\begin{array}{l}\text { Reduction } \\
\text { in } A B G\end{array}$ & $\begin{array}{l}\text { Average Pre-operative } \\
\text { ABG }\end{array}$ & $\begin{array}{l}\text { Average Post-operative } \\
\text { ABG }\end{array}$ & $\begin{array}{l}\text { Reduction } \\
\text { in } \mathrm{ABG}\end{array}$ \\
\hline Khan et al. [14] & 30.7 & 7.1 & 23.6 & 32.9 & 8.1 & 24.9 \\
\hline Kazikdas et al. [12] & 25.6 & 17.3 & 8.3 & 30.7 & 20.2 & 10.5 \\
\hline Shishegar et al. [15] & 28.5 & 14.8 & 13.7 & 25.4 & 14.0 & 11.4 \\
\hline Vashishth et al. [17] & 29.0 & 7.3 & 21.7 & 30.4 & 17.5 & 12.9 \\
\hline Demirpehlivan et al. [16] & 28.0 & 15.0 & 13.0 & 24.5 & 14.0 & 10.5 \\
\hline Weighted average (SE) & & & $20.9(7.5)$ & & & $17.9(7.0)$ \\
\hline
\end{tabular}




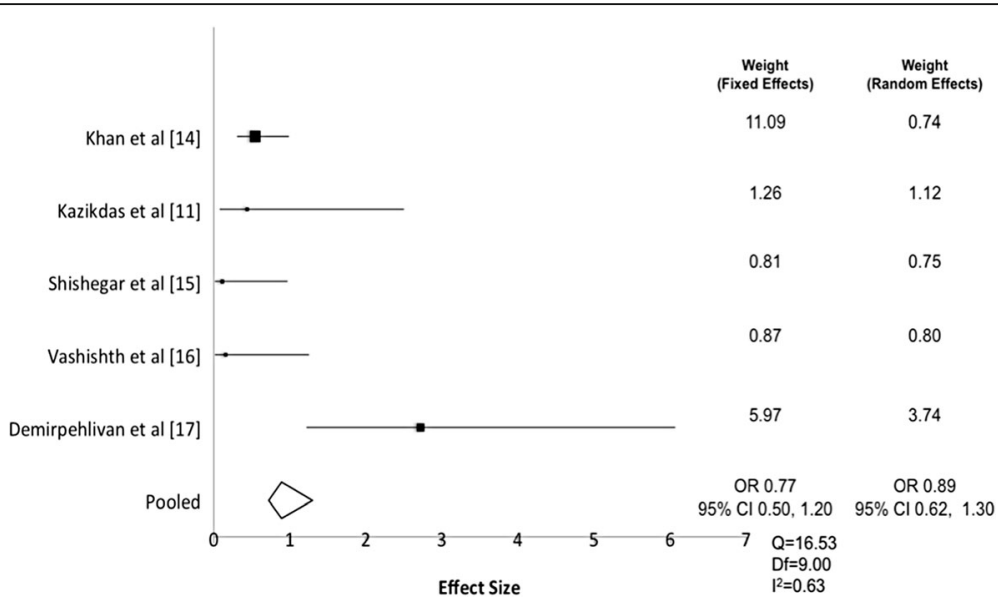

Fig. 2 Forest Plot Demonstrating Pooled OR of complications comparing palisade tyampanoplasty to temporalis fascia

systematic reviews that demonstrate superior graft integration rate with cartilage tympanoplasty compared to temporalis fascia $[8,19]$. Those studies did not examine palisade cartilage tympanoplasty alone by subgroup analysis, and thus, our systematic review and meta-analysis offers specific outcomes regarding the clinical effectiveness of this technique, the cartilage palisade tympanoplasty.

There are several limitations to this study. First, with the exception of the study by Khan et al. [14], which reported on 223 patients, the remaining studies had small cohorts of twenty three to thirty patients in the palisade group. These studies represented the results of single surgeons. In addition, there is likely significant publication and reporting bias of positive results. Since these studies are all non-randomized, selection bias remains an issue. In addition, the selection criteria used by authors for using the palisade technique was not consistent. While all the authors stated that operated ears must be dry and free of mucosal disease before surgery, the exact size criteria varied. Khan et al. included ears with "small" perforations, defined as less than $50 \%$ of the tympanic membrane and "large" perforations, defined greater than 50\% [14]. In contrast, Cabra et al. selected patients with TM perforations $>25 \%$ [3], while Kazikdas et al. included all primary tympanoplasties with $>50 \% \mathrm{TM}$ perforation [12]. Importantly, authors did not use digitally captured images prior to surgery to evaluate perforation size and there are inherent inaccuracies in the assessment and charting of perforations by subjective clinicians. Thus, future studies with large cohorts of patients need to accurately measure and report perforation size to enhance future comparability amongst surgeons and centers.

In addition to heterogeneity of perforation size, there is considerable heterogeneity in terms of patient age, comorbidities, and other risk factors for graft failure. While the random effects model for pooled odds ratio attempts to address between study variance, we are unable to explain the drivers of heterogeneity or perform subgroup analysis due to the lack of patient-level data.

Finally, we specifically limited our review to studies of older children and adult patients. To our knowledge, only one study to date specifically examined the use of cartilage palisades in the pediatric population. Vashishth et al. examined outcomes of cartilage palisades over temporalis fascia at 6 months and 1 year in children and adult patients [17]. Although the authors demonstrated excellent results in the palisade group, we were unable to extract data for subgroup analysis (i.e. adult only or pediatric only) and thus excluded their paper from this review. However, given the paucity of literature and lack of consensus regarding pediatric tympanoplasty methods and outcomes, this represents an area in need of better research. Finally, the endoscopic approach to tympanoplasty is gaining popularity in Canada [20], but its adoption for the palisade tympanoplasty technique is unstudied.

\section{Conclusions}

There is evidence that cartilage palisade tympanoplasty offers excellent graft take rates and good postoperative hearing outcomes for perforations of various sizes and for both primary and revision cases. This technique has predictable, long-term results with low complication rates, similar to temporalis fascia tympanoplasty.

\section{Abbreviations}

OR: Odds ratio; TM: Tympanic membrane

\section{Acknowledgements \\ None. \\ Funding \\ None.}

Availability of data and materials

Primary data and analysis are available upon request. 


\section{Authors' contributions}

CCJ, CS, AH designed the study. CCJ, CS, and CA collected the data and performed data analysis. CCJ and CS prepare the abstract. All authors reviewed the finalized manuscript in preparation for submission. All authors read and approved the final manuscript.

\section{Authors' information}

None.

\section{Competing interests}

The authors declare that they have no competing interests.

\section{Consent for publication}

All authors have reviewed the manuscript and consent to publication.

\section{Ethics approval and consent to participate}

Not applicable.

\section{Publisher's Note}

Springer Nature remains neutral with regard to jurisdictional claims in published maps and institutional affiliations.

Received: 6 May 2017 Accepted: 7 June 2017

Published online: 17 June 2017

\section{References}

1. Dornhoffer J. Cartilage tympanoplasty: indications, techniques, and outcomes in a 1,000-patient series. Laryngoscope. 2003;113:1844-56.

2. Dornhoffer JL. Cartilage tympanoplasty. Otolaryngol Clin North Am. 2006:39:1161-76.

3. Cabra J, Monux A. Efficacy of cartilage palisade tympanoplasty: Randomized controlled trial. Otol Neurotol. 2010;31:589-95.

4. Neumann A, Schultz-Coulon HJ, Jahnke K. Type III tympanoplasty applying the palisade cartilage technique: a study of 61 cases. Otol Neurotol. 2003;24:33-7.

5. Velepic M, Bonifacic M, Manestar D. Cartilage palisade tympanoplasty and diving. Otol Neurotol. 2001;22:430-2.

6. Gerber MJ, Mason JC, Lambert PR. Hearing results after primary cartilage tympanoplasty. Laryngoscope. 2000;110:1994-9.

7. Neumann A, Jahnke K. Reconstruction of the tympanic membrane applying cartilage: indications, techniques and results. HNO. 2005;53:573-84. quiz 585-6.

8. Mohamad SH, Khan I, Hussain SS. Is cartilage tympanoplasty more effective than fascia tympanoplasty? A systematic review. Otol Neurotol. 2012;33:699-705.

9. Tos M. Cartilage tympanoplasty. Stuttgart, New York: Thieme; 2009. in print.

10. Tos M. Cartilage tympanoplasty methods: proposal of a classification. Otolaryngol Head Neck Surg. 2008;139:747-58.

11. Man SC, Nunez DA. Tympanoplasty-conchal cavum approach. J Otolaryngol Head Neck Surg. 2016;45:1.

12. Kazikdas KC, Onal K, Boyraz I, Karabulut E. Palisade cartilage tympanoplasty for management of subtotal perforations: a comparison with the temporalis fascia technique. Eur Arch Otorhinolaryngol. 2007;264:985-9.

13. Neumann A, Hennig A, Schultz-Coulon HJ. Morphological and functional results of Palisade Cartilage Tympanoplasty. HNO. 2002;50:935-9.

14. Khan MM, Parab SR. Comparative study of sliced tragal cartilage and temporalis fascia in type I tympanoplasty. J Laryngol Otol. 2015;129:16-22.

15. Shishegar M, Faramarzi A, Taraghi A. A Short-term Comparison Between Result of Palisade Cartilage Tympanoplasty and Temporalis Fascia Technique. Iran J Otorhinolaryngol. 2012;24:105-12.

16. Demirpehlivan IA, Onal K, Arslanoglu S, Songu M, Ciger E, Can N. Comparison of different tympanic membrane reconstruction techniques in type I tympanoplasty. Eur Arch Otorhinolaryngol. 2011;268:471-4.

17. Vashishth A, Mathur NN, Choudhary SR, Bhardwaj A. Clinical advantages of cartilage palisades over temporalis fascia in type I tympanoplasty. Auris Nasus Larynx. 2014:41:422-7.

18. Uzun C, Cayé-Thomasen P, Andersen J, Tos M. A tympanometric comparison of tympanoplasty with cartilage palisades or fascia after surgery for tensa cholesteatoma in children. Laryngoscope. 2003;113:1751-7.

19. Yang $T$, Wu X, Peng $X$, Zhang $Y$, Xie S, Sun H. Comparison of cartilage graft and fascia in type 1 tympanoplasty: systematic review and meta-analysis. Acta Otolaryngol. 2016;136(11):1085-90. Epub 2016 Jun 16.

20. Yong M, Mijovic T, Lea J. Endoscopic ear surgery in Canada: a crosssectional study. J Otolaryngol Head Neck Surg. 2016;45:4.

\section{Submit your next manuscript to BioMed Central and we will help you at every step:}

- We accept pre-submission inquiries

- Our selector tool helps you to find the most relevant journal

- We provide round the clock customer support

- Convenient online submission

- Thorough peer review

- Inclusion in PubMed and all major indexing services

- Maximum visibility for your research

Submit your manuscript at www.biomedcentral.com/submit
Biomed Central 